\title{
Taking care of the laundry in care homes
}

\author{
Jayne Lloyd
}

This chapter discusses how artists' performative engagements with processes of caring for objects can establish new models of relational care with and for older people residing in care homes, especially those living with dementia. The chapter focuses on an art project I created and led in a care home in south London in 2014 as part of my PhD. ${ }^{1}$ In my examination of what this project set out to do and what it achieved, I apply Fisher and Tronto's (1990) definition of 'caring about' and 'caregiving' to processes of caring for objects. I consider how relationships with everyday objects and certain acts of domestic labour became meaningful acts of self-care for an elderly care home resident living with dementia who participated in the project. Fisher and Tronto define caring about as involving 'paying attention to our world in such a way that we focus on continuity, maintenance, and repair' (1990: 40). They define caregiving as the labour involved in that maintenance and repair and include objects in the scope of what can be cared for, but it is not the focus of their research. In this chapter, I argue that the care of objects could form an important part of care ethics because the performance of the processes involved in their maintenance and repair can be an important vehicle for caring for the self and other people. I want to make the claim that to build a more caring, nurturing - identity-enhancing life in care homes, residents need to experience a performed engagement with the care of objects that was part of their everyday routines before they entered institutionalised care.

The project I discuss included a series of ten-hour-long weekly sessions that took place in a care home living room. It was attended by a group of eight residents and two paid caregivers. It was the second in a series of five projects I designed in response to sessions I observed that were delivered by the Age Exchange Theatre Trust who developed 'reminiscence arts' sessions. The reminiscence arts sessions combined a range of arts practices, including drama, dance, music and visual arts, and aimed to support individuals and groups of care home residents and professional caregivers in 
their exploration and communication of stories about their lives. I observed that many of the stories told verbally or embodied in actions and interactions drew on everyday domestic activities such as gardening, cooking and cleaning that involved caring for objects and environments as well as people. My research aimed to interrogate and further develop aspects of Age Exchange's performance of everyday practices and develop an understanding of how the tasks and activities people regularly perform as part of their daily lives could become artistic practices. I wanted to understand how these practices retained a relevance to people's identity once they had moved into care, where the tasks involved in maintaining the care home were usually performed for them instead of by or with them. I designed and delivered five of my own projects themed around different everyday practices: doing the laundry, walking in different weather and environments, cooking, walking a dog and sharing meals. In the sessions, I brought in objects and materials used in these everyday practices and created simple sensory environments that evoked the lighting, texture, colour and smell of aspects of the processes and environments in which they took place. These were combined with arts materials and art-making activities.

I am a visual artist and researcher and collaborated with Christina Argyropoulou on the project, a dancer who facilitated some of the Age Exchange sessions I observed. The theme of the project was walking in different weather conditions and environments but this chapter focuses on how Betty, a care home resident living with dementia who participated in the project, introduced a different theme by performing the act of doing the laundry in the sessions. ${ }^{2}$ My first PhD project focused on laundry processes, but it was not a theme I expected to engage with in this project. The following is a description of how Betty interpreted arts materials and props included in the sessions for other purposes to perform actions involved in doing the laundry and other cleaning processes:

Christina Argyropoulou and I hung a white sheet up in front of the small group of care home residents, back lit it and began moving cut-outs of people, plants and animals behind it to create silhouettes. It was part of a session themed around night-time. Before we had finished our story, Betty, a member of the group, who, only seconds earlier, was laughing and watching the shadows intently, stood up and began unpegging the sheet. Understanding her action from previous sessions, we brought our performance to a close and transitioned into folding the sheet with Betty. I took the other end of the sheet and followed her lead in shaking and folding it, before thanking her and putting it away on a table with the other props and art materials. Betty's folding of fabric formed part of most of our ten sessions together. We would facilitate an interaction with a piece of darkcoloured bejewelled fabric to evoke a starry sky or blue fabric to evoke a summer's day or swimming pool and, at some point, Betty would get up and that would mark the end of the performance and the start of a new one that involved clearing away. Betty never verbally told us anything about her actions; we knew, however, from Betty's other interactions with objects and materials in the sessions, for example, using paint sponges to clean 
umbrellas or sweeping up flour we were shaking over stencils, that it was a form of domestic cleaning and, in the case of the sheet folding, part of the process of doing the laundry.

Betty's performance of doing the laundry in the arts sessions did not contribute to the continuity, maintenance or repair of clothing or fabrics in the care home. I propose instead that it was a form of self-care that involves the performance of care for objects and materials as a way of maintaining and providing some continuity and, perhaps, repair of Betty's identity, which could be considered incomplete if activities that form and express aspects of who she is are lost on entering institutional care. The way I propose Betty cared for herself through performing processes that cared for objects suggests that interactions with the material world have a role to play in caring for the self and other people. One way to conceptualise the relationality between people and processes that care for objects is to include objects as an integral part of the existing concept of a relationship-centred approach to care. A relationship-centred approach is already applied to care practices, although not as prevalently as a person-centred approach that focuses on the individual's care needs rather than placing an emphasis on the network of relationships that support people's lives. A relationship-centred approach to care proposes that 'relationships are critical to the care provided by nearly all practitioners (regardless of discipline or subspecialty) and a source of satisfaction and positive outcomes for patients and practitioners' (Tresolini and the Pew-Fetzer Task Force, 1994: 11). The relationships they propose are particularly important to the quality of care relationships between people. This chapter proposes that the integration of objects into relationship-centred care could make a contribution to improving practices and concepts of care by recognising that the web of relations that support a person's sense of self goes beyond interactions between people. Further, the inclusion of objects could make a contribution to care ethics by productively developing Held's relational concept of care ethics that, in a similar way to the relationship-centred approach to care, asserts that ' $\mathrm{t}$ ] he values of caring are especially exemplified in caring relations, rather than in persons as individuals' (2006: 42).

In the remainder of the chapter, I discuss Betty's engagement with laundry practices in the art sessions to further explore how a relational approach to care that involves the performance of care for objects can support care home residents' identities and to build an understanding of the specific role artistic processes can play in care. First, I identify how the role of looking after objects is lost when older people, especially those living with dementia, enter institutional care and I argue that this loss can have a significant impact on their sense of self. Second, I propose an important role for framing everyday domestic practices as performances in art sessions. I argue that enacting aspects of certain domestic processes in this context supports tacit skills and knowledge that are embedded in these processes and that form part of care home residents' identities to be communicated and valued. Third, I propose that there is a focus with which artists pay attention, value 
and respond to care home residents' interactions with material processes that is specific to their artistic processes and has the potential to have wider implications for concepts of care and care practices.

\section{Institutionalised care and the loss of the care of objects}

On entering institutionalised care, Betty lost the role of looking after objects, including her clothing that she no longer laundered. Yet Betty performed the actions involved in doing the laundry during the art sessions, suggesting these seemingly redundant processes still held a significance for her. Tasks involved in caring for objects could be important to her because before entering care they were part of her ongoing creation of home, which supported aspects of her sense of self. If these actions are no longer completed the skills, knowledge and associations embodied in them stop being renewed and brought into the present through their enactment. The loss of the maintenance of a home and the objects and materials that comprise it therefore can signify the decline of a resident's sense of identity. This loss is, in part at least, a result of entering 'total institutions', a term Goffman first applied to care homes in 1961. He defines total institutions as 'a place of residence and work where a large number of like-situated individuals, cut off from wider society for an appreciable period of time, together lead an enclosed, formally administered round of life' (Goffman, 1990: 11).

On entering these closed communities, Goffman describes how practices from their previous 'home world' are discarded as the residents are inducted into the routines and practices of the institution. The everyday practices of older people, especially those living with dementia, are likely to begin to change and diminish before entering care as levels of care and support are introduced prior to their admission. Now 'batch living' (Goffman, 1991), however, their daily routines must conform much more abruptly to those set by the institution, and they are treated and expected to behave similarly to their co-residents, despite having life experiences and domestic practices that were established before entering it. There was no place for Betty's enactments of the laundry process in the care home laundry or in working alongside the paid staff who were responsible for the maintenance of the care home and the care of its residents. Further, Betty's enactment of actions involved in laundry practices could be understood as the performance of an 'occupational remnant' (Gibson, 2006), an action developed by someone living with dementia before entering care that can in the absence of its previous context appear out of place. This can lead to the actions being misunderstood, dismissed and discouraged.

Sarah Pink's (2012) research into the laundry practices of middleaged women who maintained their own homes gives an insight into the important role laundry practices can play in the ongoing formation of a person's identity and how laundry practices are developed as part of the creation and maintenance of a material, social and multi-sensory home. I 
introduce her research here to begin to build an understanding of how the care of objects is entwined with self-care and to highlight how aspects of identity that are supported by the completion of these processes are lost when someone enters institutional care. Her research into laundry practices was conducted following the principles and methodologies of her sensory ethnography practice, which pays close attention to the performance and multi-sensorality of everyday practices in order to understand the personal and social meanings they hold. She carefully listens with all her senses to her research participants' verbal and non-verbal descriptions of their laundry as they take her on tours of their homes.

Pink coined the term 'laundry lines' to describe how clothing, soft furnishing, towels and other washable items move in the home before, after and during washing as part of a domestic cycle. The concept of laundry lines extends what is categorised as laundry by expanding the duration of time an item is considered to be laundry beyond clothing and other items when they are in the washing machine or hanging on the washing line, to items at different stages of cleanliness in use in the home and beyond; for example, the curtains hung at the window or the shirt a research participant is wearing or is folded in their drawer. Following the laundry lines through their cycles highlights how the act of doing the laundry relates to other aspects of the research participants' lives and uncovers how laundry contributes to the 'multi-sensory home' and the identity of its inhabitants (Pink, 2012). Pink describes how laundry is a relational process that plays an important part in the ecology of a home:

[L]aundry is moved through a home it is not moving in the home, but is moving as part of the home, and in relation to the other things that make up home. Laundry is part of the ecology of things that make the textures, smells and visual appearance of home and the affective affordances of home and it is embedded in the socialities of home. Laundry practices therefore are integral to the constitution of the sensory home. The laundry lines that these practices are interwoven with thus participate in the making of home as a place-event. (2012: 76-7, original emphasis)

The laundry lines of a domestic home are specific to the inhabitants that continuously create and maintain them and, as Pink's research attests, integral to the ongoing formation of an individual's home. In care homes, the inhabitants do not do their own laundry. The laundry lines are disjointed as different aspects of the laundry process are performed by different people often out of view of the residents who only encounter the laundry when it is in use as part of their environment or clothing. The process of caring for the laundry is further removed from the residents because in care homes most domestic labour is a backroom activity (Goffman, 1991) spatially segregated from the residents' living quarters. Betty's enactments of aspects of the laundry process are instances of a resident engaging with a domestic activity in a communal area of a care home. However, her actions did not form part of the laundry lines or everyday maintenance of the home. This prompts questions that I engage with in the following section about the specific role 
performing certain domestic processes in the context of an art session can play in supporting care home residents' sense of identity.

\section{Framing domestic performances in art sessions}

There were important differences between how Betty's laundry practice was framed in the context of an art session and how laundry is done in everyday life. Her laundry practice had become performative: her actions had lost their practical application, she repurposed materials and spaces that were available to her in the session to improvise a version of her laundry practice, and she was observed by a small audience that included other care home residents and professional caregivers participating in the group, my co-facilitator and myself. Her performance enabled the qualities of the laundry process to be paid attention by her audience who watched and were encouraged by Christina Argyropoulou to mirror her actions and mime parts of their own laundry practices in response. This kind of attention is rarely paid to everyday practices, which are often overlooked. The context of an art session, therefore, can provide an opportunity for a different and, perhaps, deeper engagement with certain domestic processes than is possible in everyday life.

The processes undertaken to care for objects in everyday life are embodied experiences and the tacit skills and knowledge required to complete them are rarely consciously considered, voiced, shared or even acknowledged or understood. Pink's research is relevant again here. It highlights that the complex multi-sensory actions, skills and knowing involved in everyday domestic practices that are integral to the creation and maintenance of home remain tacit and unacknowledged, even by those who complete the tasks: 'Doing the laundry is one of the skilled multisensory practices of everyday domestic life. It involves embodied knowing, sensing, ways of doing that are rarely articulated verbally, but that are essential to the successful accomplishment of its various stages and to the constitution of the home as place' (Pink, 2012: 71).

A similar lack of understanding and interest in understanding the embodied and tacit knowledge involved in care is identified by Fisher and Tronto (1990). They account for the lack of attention paid to how caring processes are accomplished by citing the incredible wealth of experience of caring for others that women accumulate in their everyday lives. They write:

$[\mathrm{N}]$ one of these images of carers fully examined caring itself; they were focussed much more on the actors than on the activity. There are two main reasons for this lack of attention to caring itself: one is the tremendous fund of everyday experience that women especially have concerning caring. This experience encourages us to think that we already 'know' what caring is. (Fisher and Tronto, 1990: 36)

There are limitations to what can be communicated and understood about the context of Betty's actions in a non-verbal performance, and I do not 
have any other information about her laundry practices than what was expressed through her enactments of them. Her dementia had impaired her ability to communicate verbally but she was still able to confidently perform an embodied recollection of these practices. Through her performances, the tacit skills and knowledge Betty needed to have developed to complete the processes were made explicit in the sessions. This happened because, as described at the start of this section, the everyday practice became performative and was witnessed and responded to by an audience. An attention was paid to her enactment of an everyday practice that valued the experience it embodied. Performing actions that care for objects in an art session can offer a space to appreciate the specific qualities of these caring acts. Further, the change in context of Betty's laundry practice from the everyday to an art session shifted not only how it was viewed and valued but also what Betty cared for through her actions. The laundry processes Betty used to complete before entering residential care would have provided maintenance, continuity and repair of clothing and other fabrics and can be understood as a form of caring about and caregiving as defined by Fisher and Tronto (1990). When they were enacted in the group, however, they did not support the maintenance or continuity of the care home. What was being cared for through Betty's interactions in the group was her identity. The value the audience's engagement with her laundry practice placed on her performance had the potential to support her sense of self. Performing her laundry practice for her caregivers and fellow care home residents has the potential to strengthen her relationships with them by enabling them to know more about her and through her seeing that they are paying attention to what she was communicating about herself.

I have argued in this section that it is the context of the art session that frames domestic acts that care for objects in such a way that they become performative and this enables attention to be paid to them by those participating in the group. Artists can be instrumental in establishing contexts for themselves and others to share in a type of attention that enables reciprocal processes that support caring relationships. Chrissie Tiller (2017) proposes that artists can be particularly skilled at revealing the tacit skills of communities and if these can be uncovered and valued then they can support members of communities to recognise how they are contributing to the collaboration. She observes that when artists engage with communities, reciprocity is important in moving towards an equality of exchange. She argues that reciprocity depends on both parties believing they have something equally important or useful to give and to gain. In the next section, I explore what is specific about artists' processes that enables them to create a space for reciprocal caring interactions that involve people and objects.

\section{The role of artistic processes in relational care}

In one of the sessions, I folded a sheet with Betty. Folding a sheet with her raised my awareness of the role of my own embodied knowledge in the 
activity and it gave me an understanding of how the materials and objects with which we interacted affected our engagement with each other. In this section, I consider this act to discuss how folding a sheet is a relational process that involves the movements of people and objects. I propose that the sensory attunement and aesthetic sensibility I have developed as part of my art practice enabled me to understand and respond to this everyday act in a way that facilitated a specific kind of relational care.

Holding the opposite end of the sheet to Betty, I was connected to her through its material. As she moved to fold the sheet lengthways twice before folding it in half the other way, I instinctively moved to fold it in half first. I realised this was different to my usual laundry practice. When she shook the sheet, I had to tune in to her rhythms to enable the sheet to move freely between us and to stop the flow of my laundry practice disrupting hers. We both held very specific embodied knowledge of this process, and we needed to respond to each other and the material and spatial qualities of the sheet in order to share in the activity. Before folding the sheet with Betty, I had not thought about or even consciously known how I folded a sheet. By making me pay attention to my actions Betty had taught me, not only about her laundry practice, but also about my own. I realised that the interaction provided the opportunity for mutual care and learning. It was not only about caring for Betty's identity but by raising my awareness of my tacit knowledge of my laundry process I could gain an understanding of an aspect of my own identity. This awareness has applications to my sense of self in my everyday life and builds on my knowledge as an artist of the performative, material and collaborative qualities of everyday acts. In the example of my interaction with Betty, we both uncovered each other's tacit skills.

While this encounter could have happened between two people who were not artists, I argue that the level of care and attention that I paid to the details of the materiality, movement and meaning of the interaction happened because of how I engage with the world through the processes I use to make artwork. My artistic practice includes materials, and this helped me to recognise that the reciprocity of my exchange with Betty happened not only through our relationship to each other but also in relation to the sheet, which was a vital aspect of the exchange. My interaction with Betty and the sheet could be conceptualised as a non-verbal conversation through which we communicated our embodied knowledge to each other. Understood in this way, it illustrates how artists can initiate a form of communication that is mediated through an engagement with objects and materials. Artists are able to communicate in this way because they look at the world with an attentiveness and care that breaks down what they see.

In his essay, Eye and Mind (1964), Merleau-Ponty explains how and why painters view the world differently to most other people. He argues that for painters to create a representation of the world on a canvas they must become aware of what they see in front of them. People who are not painters are not required to see in the same way and, therefore, overlook a lot of what painters train themselves to become aware of. He proposes that people 
see in light. However, the light is instinctively reconstructed into a spatial vision of material objects with texture and form. Therefore, only the object is perceived, not the light and shadow that make it visible. He describes the process of seeing as follows:

Everyone with eyes has at some time or other witnessed this play of shadows, or something like it, and has been made by it to see things and a space. But it worked in them without them; it hid to make the object visible. To see the object, it was necessary not to see the play of shadows and light around it. The visible in the profane sense forgets its premises; it rests upon a total visibility which is to be recreated and which liberates the phantoms captive in it. (Merleau-Ponty, 1964: 133)

Tim Ingold's extension of Merleau-Ponty's experience of the world through vision to other senses is helpful in applying Merleau-Ponty's ideas about how painters see to how artists with more performative and multi-sensory practices interact with the world. Ingold proposes that if, as Merleau-Ponty argues, we see in light then an equivalent of what goes for vision should also go for auditory and tactile perception.

If we can see things because we first can see, so too, we can hear things because we first can hear, and touch things because we first can feel. The sight, hearing and touch of things are grounded in the experience, respectively, of light, sound and feeling. And if the former force us to attend to the surface of things, the latter, by contrast, redirect our attention to the medium in which things take shape and in which they may also be dissolved. (Ingold, 2011: 135)

Drawing on Ingold, if painters break down the process of seeing to enable them to understand what they are looking at and, in turn, to paint it, is it not, therefore, possible that sculptors and craft artists do the same with materials, musicians with sound and dancers with movement? The attentiveness Merleau-Ponty and Ingold propose that artistic processes involve, I argue, can be employed in art sessions to mediate a form of communication with other people. This can be understood as the sensory attunement and aesthetic sensibility of the artistic process enabling 'total communication' (Fox and Macpherson, 2015). Fox defines 'total communication' as a careful listening with and through materials and gestures (Fox and Macpherson, 2015). The practice of making art together enables a prolonged focused attentiveness on the participants and an openness in listening and responding to what is being communicated. Folding the sheet with Betty is an example of 'total communication' in which we carefully 'listened' with and through the movements and materiality of the sheet to each other's embodied stories. Further, I propose that the way Betty's laundry process was engaged with in the art sessions illustrates how relational care built on an understanding, valuing of and response to another person's tacit skills and knowledge can be practised. Not only valuing the meaningfulness these tacit skills and knowledge hold for care home resident's identity but also what they can bring to 
an exchange in terms of enabling an understanding of and engagement with one's own skills and knowledge is particularly important because it enables care home residents to give something - to provide care. This is significant to a relational approach to care because care home residents have paid caregivers to attend to their personal care needs but they have few opportunities to care for others or to share their skills and knowledge.

\section{The performative care of objects in institutional care settings}

In this chapter, I have argued for a relational approach to care that recognises how engaging with everyday domestic processes that care for objects can play an integral role in self-care and caring for other people. I have proposed that opportunities to perform processes that care for objects should be part of the care received by older people living in residential care homes. This assertion is a response to the significant impact entering institutionalised care can have on older people's sense of identity, particularly those living with dementia. A decline in a care home resident's sense of self can, in part, be the result of the lack of opportunities they have to care for others or look after their own home by completing certain domestic processes that involve the maintenance and repair of objects. Residential care provision is round-the-clock, and the types of processes I am concerned with are completed regularly as an integral part of the day-to-day maintenance of a home. Supporting residents to participate in the everyday domestic processes that maintain the care home would be the most obvious solution to addressing the loss of these activities in their lives. In this chapter, however, I have made a different proposition. I have argued that there is a specific benefit to these processes being performed and framed in the context of an art session.

Betty's performance of her laundry practice is one small example of how a meaningful interaction can be mediated through an object. Concepts and practices of care cannot be changed on the strength of such a small moment of practice; however, this small moment does illustrate the powerful way attentiveness to the embodied skills of residents can help facilitate a form of relational care. The performances bring domestic processes that are usually backroom activities into the heart of the care home and introduce into the place in which they currently reside aspects of care home residents' lives that are lost when they enter institutional care. Enacting these practices in the context of an art session has a specific role to play in enabling the tacit skills, knowledge and embodied experiences required to accomplish them to be communicated and valued. The art session frames them as a performance and as part of an artistic process in which the performative, material, sensory and aesthetic qualities of the process can be shared. Through the performance and witnessing of these acts, a reciprocal form of care can take place during which those involved learn something about and from each other.

Fisher and Tronto propose that 'skills in perception and trained attention may shape what we care about' (1990: 42). Art processes and performances 
of everyday activities make otherwise overlooked and undervalued processes of caring explicit, and this could have wider application than the specific art session context I have discussed. This way of engaging with and understanding the world is the contribution I propose artists engaging with everyday acts can make to care. There are significant challenges and further considerations that are beyond the scope of this chapter to applying a practice developed in an art session to the context of the everyday life of institutional care. The sensory and aesthetic orientation of the artistic processes I have discussed have been developed over time as part of an art practice and cannot be quickly and easily acquired. It is likely, therefore, that while it may be desirable to adapt and embed care practices that involve the care of objects as a form of self-care in the everyday life of the care home, there is still an ongoing role for artists' performative engagements with and within care.

\section{Notes}

1 My research was part of Reminiscence Arts and Dementia Care: Impact on Quality of Life (RADIQL, 2012-15), a three-year programme of creative activities for and with care home residents living with dementia. It was funded by Guy's and St Thomas' Charity and delivered by Age Exchange Theatre Trust.

2 Name changed to conceal identity in accordance with the ethical approval the research received. 